Cristiane Lisbôa da Conceição ${ }^{a}$ (iD) https://orcid.org/0000-0002-7557-3861

Roberta Pereira Furtado da Rosa ${ }^{b}$ iD https://orcid.org/0000-0002-2132-1829

Katia Maria Teixeira Santorum ${ }^{\mathrm{c}}$ (iD) https://orcid.org/0000-0003-2830-157X

a Universidade Federal Fluminense, Instituto de Psicologia. Niterói, RJ, Brasil.

b Instituto Federal de Educação Ciência e Tecnologia do Rio de Janeiro. Rio de Janeiro, RJ, Brasil.

'Universidade do Estado do Rio de Janeiro, Instituto de Psicologia. Rio de Janeiro, RJ, Brasil.

Contato:

Cristiane Lisbôa da Conceição

Email:

cristianelisboa@gmail.com

Trabalho baseado na dissertação de mestrado de Cristiane Lisbôa da Conceição, intitulada $A$ formação pela ação: experimentando o ofício de analista do trabalho pela perspectiva da clínica da atividade, pela Universidade Federal Fluminense, Niterói, 2016. Baseado também na tese de doutorado de Roberta Pereira Furtado da Rosa, intitulada Terapia ocupacional e clínica da atividade: intercessões nos debates da atividade de formação, pela Universidade Federal Fluminense, Niterói, 2017.

Os autores informam que este trabalho foi realizado com apoio da Coordenação de Aperfeiçoamento de Pessoal de Nível Superior - Brasil (CAPES) - Código de Financiamento 001 "This study was financed in part by the Coordenação de Aperfeiçoamento de Pessoal de Nível Superior - Brasil (CAPES) - Finance Code 001".

Os autores declaram que não há conflitos de interesses.

Os autores informam que o trabalho não foi apresentado em eventos científicos.

Recebido: 07/02/2018

Revisado: 22/06/2018

Aceito: 25/06/2018

\section{Intervindo nos processos de formação para o cuidado em saúde: uma experiência com o método de instruções ao sósia}

\author{
Intervening in the health care training processes: an experience \\ with the method of instructions to the double
}

\section{Resumo}

Introdução: apresentam-se reflexões sobre a atividade de formação em saúde, no âmbito da graduação, oriundas de pesquisa e intervenção que tiveram como campo o dispositivo de formação Programa de Educação pelo Trabalho para a Saúde (PET-Saúde), desenvolvido em uma instituição de ensino superior do estado do Rio de Janeiro. Objetivos: analisar a atividade desenvolvida no PET-Saúde a fim de interferir no contexto de formação e de adoecimento que vem sendo relatado por estudantes, de modo a fortalecer e ampliar seus recursos para a ação. Métodos: empregamos o método de instruções ao sósia por meio da perspectiva da clínica da atividade. Resultados: a intervenção possibilitou não só explicitar e compartilhar os recursos para ação que têm sido construídos coletivamente e pessoalmente pelos estudantes, mas também discutir os critérios de um trabalho bem feito nas práticas de cuidado em saúde. Conclusão: constatamos que encarar a formação como meio de desenvolvimento de recursos para a ação a torna um processo mais potente, tanto em sua eficácia quanto em seu potencial em produzir saúde. Para isso, afirmamos a imprescindibilidade de viver os conflitos da atividade de trabalho para o qual se quer formar, conjugada com espaços coletivos de discussão das experiências vividas nos dispositivos de formação.

Palavras-chave: atividade; formação; cuidado; clínica da atividade.

\begin{abstract}
Introduction: this paper presents reflections on the health training activity, within the scope of graduation, after research and intervention in the field of the training device named "Education Program through Work for Health" (PETSaúde), produced at a higher education institution in Rio de Janeiro (Brazil). Objective: to analyze the activity pursued in PET-Saúde to interfere in the context of training and illness reported by students, in order to strengthen and expand their resources for action. Methods: we employed the instructions to the double method through the clinic of activity perspective. Results: intervention allowed not only to explain and share the resources for action that have been built collectively and individually by students, but also to discuss the criteria, in health care practices, for a well done job. Conclusion: we evidenced that, when we face training as a means for developing action resources, we change it into a more powerful process, both in its effectiveness and in its potential to produce health. In order to reach this aim we affirm that both are indispensable: engagement in the conflicts of the work activity we want to be trained and the collective spaces for discussion about the experiences assimilated in the training devices.
\end{abstract}

Keywords: activity; education; care; clinic of activity. 


\section{Introdução}

As indagações que originaram a pesquisa e intervenção abordadas neste artigo foram disparadas por relatos de estudantes de cursos de graduação em saúde de instituições públicas de ensino superior (IES) no estado do Rio de Janeiro. Nesses relatos, uma queixa específica chama atenção: a alta carga de trabalho, que envolve o estudo fora de sala de aula, grande quantidade de disciplinas e conteúdos por semestre além de tempo insuficiente para aprofundá-los. Nesse contexto, os relatos evidenciam sofrimento e adoecimento, fazendo precipitar uma questão: como um processo de formação que tem por objetivo "ensinar a produzir saúde" pode estar produzindo adoecimento?

Por outro lado, também deparamos com estudantes que, mesmo se queixando do excesso de tarefas, solicitam participar de projetos de pesquisa e extensão, estágios não obrigatórios, organização de simpósios e estão sempre "antenados" com relação a esses e outros eventos que compõem a carga horária complementar e extracurricular. Curiosamente, as reclamações voltadas ao excesso de tarefas mencionam conteúdos obrigatórios - ligados à grade curricular - e esses acabam concorrendo com o engajamento em outros dispositivos de formação não obrigatórios.

Essas questões nutriram o interesse em construir como objeto de pesquisa e intervenção a atividade de formação em saúde no âmbito da graduação, partindo de uma aposta no trabalho como operador de saúde ${ }^{1}$. Nesse sentido, acreditamos, junto às clínicas do trabalho e à concepção de saúde de Canguilhem ${ }^{2}$ que, nas situações de trabalho, os sujeitos nunca estão passivos, mesmo que sofrimento e adoecimento estejam presentes. Isso significa dizer que eles inventam saídas para gerir os impasses e lidar com os conflitos inéditos que se apresentam no curso da ação, buscando soluções, ainda que incompletas ou provisórias. Se, por um lado, os impedimentos à atividade podem configurar um contexto de adoecimento, por outro, a possibilidade das pessoas elaborarem coletivamente saídas para esses impasses caracteriza uma situação potencializadora de saúde, já que leva ao desenvolvimento de recursos para agir no meio profissional. Nesse sentido, a saúde seria uma margem de segurança diante dos desafios do real da atividade, uma possibilidade de enfrentar os impasses, procurando superá-los. Assim, ao objetivarmos, com nossa pesquisa e intervenção, interferir no contexto de formação dos estudantes de graduação na área da saúde, priorizamos o caminho de fortalecer e ampliar seus recursos para a ação, sustentando e desenvolvendo escolhas que têm sido feitas por eles.
Desse modo, elegemos como campo de investigação um dispositivo de formação não obrigatório, popular entre estudantes de uma IES no estado do Rio de Janeiro: Programa de Educação pelo Trabalho para Saúde (PET-Saúde) ${ }^{3}$. Esse programa, que seleciona por meio de editais nacionais as IES que participarão, visa promover a integração ensino-serviço-comunidade e a educação pelo trabalho ao fomento de grupos de aprendizagem tutorial inseridos em equipamentos de saúde das regiões próximas das IES selecionadas. Nesse dispositivo, produzimos uma análise da atividade dos estudantes, ancorada no posicionamento teórico-metodológico da clínica da atividade ${ }^{4,5}$, com o método de instruções ao sósia $^{4-6}$. Nessa perspectiva, concebendo a formação como uma atividade, estamos destacando o caráter processual e polifônico de nosso objeto, envolvendo diversos atores - sejam eles estudantes, professores, a instituição de ensino, a grade curricular, projetos de extensão e pesquisa, entre outros. De acordo com esse referencial, entendemos que não só é preciso conhecer para transformar, mas que, ao operar um método de análise do trabalho para conhecer, a transformação já está em curso ${ }^{4}$.

Ressaltamos nosso entendimento, tal como Osorio-da-Silva ${ }^{7}$, de que pesquisa e a intervenção são inseparáveis, ou seja, elas são - como a autora sugere - movimentos que se cruzam e coexistem em mútua interferência. Assim, nesse texto, há momentos em que nossas análises se referem mais à pesquisa e, em outros, mais à intervenção. Como destacado pela autora, "existem momentos de maior intensidade de um desses movimentos, mas nem por isso o outro deixa de existir, podendo dizer que passa então a fazer parte do real da atividade do clínico"7 (p. 160) esse vaivém entre pesquisa e intervenção.

\section{Sobre nosso objeto: a atividade de formação para o cuidado em saúde}

A formação profissional em saúde se constitui como um desafio principalmente a partir das lutas travadas no campo da saúde pública com os movimentos das reformas sanitária e psiquiátrica brasileiras nas décadas de 1970 e 1980. Desde então, uma nova perspectiva de cuidado e atenção à saúde tem sido construída, culminando na consolidação de um sistema de saúde único e universal - o Sistema Único de Saúde (SUS) - tendo em vista práticas de cuidado integral, descentralizado e territorializado.

Nessa direção, o cuidado, como tecnologia de assistência, não se limita a um conjunto de normas. Ele se realiza por meio de ações locais atentas às necessidades de cada caso. Por esse motivo, é importante que a formação profissional para esse campo 
não se restrinja a um processo de ensino pautado exclusivamente na transmissão de conteúdos, mas construa, junto aos estudantes, uma competência para o cuidado, alimentada por recursos coletivos para a ação desse profissional em formação.

Esse desafio tem engendrado, ao longo das últimas décadas, reformulações das estratégias de educação em saúde por parte dos órgãos gestores. Como afirmam Soares e Nogueira ${ }^{8}$ :

A implementação das diretrizes curriculares, pelo lado da educação, e a adoção da "integralidade" como eixo orientador dos processos de formação, pelo lado da saúde, são os nortes da política interministerial (Ministério da Saúde e da Educação) para a mudança na graduação das profissões de saúde, tendo como ideia central das propostas de mudança a aproximação da formação com as necessidades sociais (p. 13).

Tal aproximação entre saúde e educação possibilitou a criação de programas que integram ensino e serviço (como o PET-Saúde), ampliando as possibilidades de operar uma formação conectada às situações reais de trabalho no cuidado em saúde. Ao pensarmos esses dispositivos de formação pela perspectiva da clínica da atividade, percebemos que essa possibilidade é muito interessante, já que é a atividade que produz a competência e não o contrário ${ }^{9}$.

Nessa perspectiva, acompanhando um novato em seu ofício, é possível perceber que ele lança mão das prescrições, que em geral são objeto de estudo nas instituições de ensino, como subsídio para exercer sua atividade profissional. Essas prescrições, no entanto, apesar de importantes recursos, são insuficientes, já que não respondem aos imprevistos no curso da ação profissional. Isso ocorre por conta do descompasso entre trabalho prescrito e trabalho real, bem conhecido por vários autores que tomam o trabalho como objeto de análise. No caso do trabalho em saúde, como apontam Franco e Merhy ${ }^{10}$ :

...os trabalhadores de uma mesma equipe de ESF [Estratégia de Saúde da Família] agem de modo singular, na produção do cuidado, isto é, de forma diferente entre eles, mesmo que estejam sob a mesma diretriz normativa. Isso revelou que o processo de trabalho não segue um padrão, pois as práticas de cuidado se dão pela singularidade de cada um. Nesse cenário, as normas da ESF que têm como atributo padronizar as condutas dos trabalhadores, de acordo com as regras ditadas para o funcionamento do Programa, influenciam a atividade dos trabalhadores, dentro de limites muito restritos, pois quando estes se encontram em situação de trabalho, na relação com o usuário, ele próprio em ato, no seu processo de trabalho, é quem define como este cuidado se realiza (p. 151).

Assim, compartilhamos a ideia de que a completa correspondência entre a norma prescrita e a ação é ilusória, seja nos serviços, seja na indústria. Se nesta o objeto de trabalho comporta um grau de estabilidade maior - dado que em geral é inanimado - naqueles, a situação se torna ainda mais complexa, já que nos serviços o objeto de trabalho é vivo. Como comentávamos anteriormente, o cuidado não resulta da execução estrita de uma norma, mas se efetiva a partir da atividade dos trabalhadores da saúde. Na atividade, entre a organização prescrita do trabalho e o trabalhador, é possível identificar tanto um modo singular de cada trabalhador se apropriar das normas quanto um trabalho coletivo de reorganização da tarefa - compondo o gênero profissional que, para a clínica da atividade, é um patrimônio coletivo construído por todos e reconstruído continuamente ao longo da história de um ofício. O gênero profissional marca o pertencimento a um grupo, servindo como orientador da ação, sendo sempre inacabado ${ }^{4}$.

Nos termos da clínica da atividade podemos, então, dizer que o cuidado é uma prática que se dá na relação. Ele implica uma atividade dirigida que inclui o profissional em ação, o usuário do sistema de saúde que é "objeto" dessa ação e outras atividades (dele próprio ou de outras pessoas) que incidem sobre esse usuário. Isso quer dizer que o trabalho daqueles que cuidam só pode ser exercido a partir da mobilização de uma rede de relações.

Retomando as contribuições de Tosquelles ${ }^{11,12}$ à clínica da atividade, afirmamos que cuidar implica chamar à atividade, ou seja, intensificar o trânsito nessa rede de relações, mobilizando atitudes singulares e coletivas que possibilitem a abertura de novos caminhos, novas relações, expandindo o raio de ação daqueles envolvidos no ato de cuidar. Nesse processo é importante que aqueles aos quais o cuidado é destinado se reconheçam como sujeitos da ação, estabelecendo relações entre as coisas que só são possíveis a partir de sua iniciativa. Do mesmo modo, a saúde é entendida como um poder de ação sobre si e sobre o mundo, uma possibilidade de instituir normas conquistada junto aos outros, em relação ${ }^{4}$.

Essas noções de saúde e cuidado são importantes, não só para atuação dos profissionais da saúde, mas também para quem pretende analisar o trabalho. Desse modo, enquanto abordagem teórico-metodológica que orienta o agir para transformar o trabalho, a clínica da atividade propõe tomá-lo coletivamente como objeto de análise, encontrando aí uma via para cuidar do trabalhador. Tomando como exemplo a saúde dos próprios profissionais da saúde pública no Brasil, Jackson Filho ${ }^{13}$ aponta para a importância de cuidar do trabalho, analisando os fatores que impedem a atividade dos trabalhadores e colocam em risco sua saúde. 
A atividade de formação em saúde - muito mais do que a transmissão de conteúdos ou normas resultantes da objetivação de competências necessárias ao profissional do cuidado - implica, igualmente, chamar à atividade. É claro que toda prática de ensino provoca uma atividade - de pensamento, por exemplo -, mas o que propomos é torná-la mais potente buscando uma aprendizagem de conteúdos conectada com a produção de experiências situadas nos e a partir dos contextos que constituem o campo de trabalho deste profissional em formação.

Assim, parafraseando Tosquelles, como faz Clot em relação à análise do trabalho ${ }^{9}$, não se trata de fazer os estudantes (ou novatos) trabalharem para construírem competências. Trata-se de fazer trabalhar estudantes e formadores, para cuidar da formação. Ou seja, é somente colocando em marcha uma ação coletiva com todos os envolvidos na atividade formativa que se pode apreender, em ato, que estudantes e demais atores são corresponsáveis pela formação em curso. Entendemos que esse chamado à atividade, ou essa produção de experiências para cuidar da formação, pode ser efetivada com o auxílio de métodos - como é o caso das instruções ao sósia ${ }^{4-6}$ - que tomam a atividade de trabalho (neste caso, dos estudantes) como objeto de análise coletiva visando a ampliar e desenvolver seus recursos para agir.

\section{Métodos}

Apresentamos pesquisa e intervenção feitas com estudantes bolsistas do PET-Saúde desenvolvido em uma IES no estado do Rio de Janeiro no período de 2013 a 2015. O PET-Saúde se destina a fomentar grupos de aprendizagem tutorial em áreas estratégicas do SUS, desenvolvendo iniciativas de integração ensino-serviço-comunidade.

Por meio desse projeto, os estudantes se inserem em unidades de saúde pública, experimentando situações concretas de trabalho, supervisionados por preceptores/as (profissionais das unidades) e tutores/as (docentes das IES). Essa experiência, apenas, já é enriquecedora, mas para pensá-la de acordo com a clínica da atividade, é preciso avançar e lembrar que: se o trabalho, em si, não tem propriedades terapêuticas, como aponta $\mathrm{Clot}^{12}$, comentando o trabalho de Tosquelles, também não podemos afirmá-lo, apressadamente, como meio de formação. Afinal, não são raras situações de trabalho com impedimentos à atividade e bloqueios ao desenvolvimento. Se quisermos pensar o PET-Saúde como um dispositivo de formação coerente com a perspectiva da clínica da atividade e as apostas do SUS, é preciso analisar os processos nele implicados. Surge aí a demanda de intervir nesse espaço por meio de um método de análise do trabalho - o método de instruções ao sósia ${ }^{4-6}$.

Concebido no seio do movimento operário italiano na década de 1960, esse método foi criado para que se pudesse "ver" em detalhes tudo que envolvia a situação produtiva em questão, mesmo estando interditada a entrada dos analistas no local de trabalho. Constitui-se, então, um exercício de grupo em que cada trabalhador dá instruções a um eu-auxiliar, um sósia ${ }^{14}$.

Na presença de um grupo de pares do ofício analisado, o analista do trabalho ocupa esse papel de sósia e, dentro do grupo, será escolhido um voluntário que se colocará no de instrutor. Ele dará os comandos necessários para que o sósia aja como ele, substituindo-o em sua atividade de trabalho. A tarefa de instruir um outro que desconhece o ofício é interessante porque obriga o sujeito a pensar nos detalhes de sua atividade - a que horas deve chegar, o que fala e observa no seu cotidiano de trabalho, com quem conversa etc. Ao tentar reproduzir uma sequência de seu cotidiano de trabalho, o instrutor e o grupo vão se dando conta da complexidade que envolve suas ações. Eles percebem que inventam soluções importantes, utilizando sua própria experiência, para melhor lidar com obstáculos imprevisíveis do processo de produção e para gerenciar riscos ou combater a nocividade do ambiente de trabalho ${ }^{14}$. Esse método busca explicitar, compartilhar, discutir e desenvolver coletivamente diferentes modos de cada trabalhador exercer sua atividade.

Na década de 1990, na França, Clot desenvolve as instruções ao sósia segundo a metodologia da clínica da atividade. $\mathrm{O}$ método passa a ser empregado como instrumento de intervenção na perspectiva da psicologia histórico-desenvolvimental, buscando um acesso ao real da atividade por meios indiretos, nesse caso pela interlocução com o sósia. Esse exercício autoriza uma "reentrada" na ação, uma repetição sem repetição ou, ainda, o recomeço da ação em outra atividade que, agora, tem o sósia como interlocutor e a atividade de trabalho como objeto. Isso porque a verbalização das instruções é uma atividade em si, ou seja, uma atividade de linguagem sobre a atividade de trabalho, na qual se realiza o objetivo de "passar a ação pelo crivo do pensamento, não só do pesquisador, mas do próprio sujeito" 4 (p. 201), produzindo-se uma coanálise.

A análise do trabalho em clínica da atividade busca valer-se dessa duplicação da atividade provocada pela interlocução com o sósia, eventualmente retomada pelos pares, para oportunizar deslocamentos nos sentidos, abrindo outras possibilidades de ações realizáveis. A presença do sósia como 
interlocutor desse diálogo - sendo ele um estrangeiro no ofício analisado - coloca ao instrutor o desafio de não poder compartilhar sua atividade em "meias palavras" como faz com seus pares.

A tarefa do sósia é resistir à atividade do instrutor, trazendo à tona versões não naturalizadas das situações de trabalho. A cada interpelação do sósia é preciso que caminhos sedimentados no passo a passo das ações se transformem em bifurcações - ou seja, colocando obstáculos, o sósia entrava o desenrolar habitual das operações, convocando a atividade possível e impossível. Isso significa evocar não só os comportamentos realizados, mas especialmente aqueles que não o foram, e que, nem por isso, deixaram de existir. Significa trazer à tona, segundo Clot $^{5,15}$, a gênese das escolhas, promovendo uma ruptura na cadeia operatória e reabilitando o real como possível. Revela-se, aí, não só a dimensão operacional da atividade, mas sua dimensão opcional. Esse método pode levar os trabalhadores à recriação da experiência vivida, em um novo contexto, no qual eles podem vê-la de modo diferente, em um encontro com o passado que pode metamorfoseá-lo.

Para sua operacionalização, iniciamos o planejamento da pesquisa, retomando alguns aspectos técnicos do método ${ }^{4-6}$, o que culminou na construção de um roteiro de intervenção e do termo de consentimento livre e esclarecido (TCLE) submetidos e aprovados pelo Comitê de Ética em Pesquisa da IES em questão (CAAE: 35863614.0.0000.5268, parecer $\mathrm{n}^{\circ}$ 801.194). Para construir esse roteiro, também foram levados em consideração outros aspectos, como calendário acadêmico, horário e local conveniente para os estudantes. Para que essa intervenção não se caracterizasse como mais uma atividade concorrente, precisávamos adaptar o método às condições do campo. Então, foram feitos três encontros de participação voluntária, ocorridos no mesmo horário e local das reuniões de tutoria do PET-Saúde, no próprio campus de ensino, contando sempre com a presença da tutora.

Os estudantes foram convidados pessoalmente e por e-mail para o primeiro encontro, sendo apresentada a proposta de pesquisa e intervenção. Nessa apresentação, os 12 estudantes presentes demonstraram interesse, tanto pelos aspectos operacionais quanto teóricos. Após sanar dúvidas, pactuamos os próximos encontros, apresentando as implicações do TCLE, tais como gravação em áudio e transcrição dos encontros seguintes.

No segundo encontro, explicitamos as regras do exercício de instruções ao sósia, esclarecendo o papel do instrutor, do sósia e do grupo de pares. Em seguida, o grupo escolheu a instrutora e a sequência de trabalho que seria objeto das instruções. Por cerca de uma hora, somente a sósia (pesquisadora) e a instrutora (estudante) tinham a palavra. Logo depois, o grupo de pares presente e a tutora deixaram de ser apenas observadores e ocuparam também o lugar de sósia, prosseguindo com as interpelações típicas desse papel. Ao final, a pesquisadora encerrou o exercício questionando quanto às sensações e impressões da instrutora e grupo de pares. Esse breve momento serviu para dar vazão a possíveis mobilizações emocionais, levantando questões provocadas pelo exercício, que seriam objeto de discussão no terceiro encontro.

Como sugerem as proposições de $\mathrm{Clot}^{4,5}$, a gravação em áudio feita no dia do exercício foi entregue à instrutora, para que esta procedesse com a autoconfrontação mediada, agora não pelos questionamentos da sósia, mas pela escuta do áudio de suas próprias instruções. Nesse ponto, julgamos que a tarefa de transcrição do áudio pela instrutora não seria adequada. Optamos pela escuta e elaboração de comentários por parte da instrutora, a serem compartilhados com seu grupo de pares no encontro seguinte.

Por fim, iniciamos o terceiro encontro com esses comentários da instrutora e, logo depois, com comentários do grupo, que não teve acesso ao áudio do exercício. O conteúdo desses encontros será discutido na seção a seguir.

\section{Resultados e Discussão}

A partir da operação do método, o primeiro ponto a ser destacado é que, apesar do grupo analisado estudantes do PET-Saúde - atuar em dois serviços diferentes - Ambulatórios de Saúde Mental e ESF ele era, por um lado, suficientemente homogêneo para que se estabelecesse uma sequência de trabalho em comum - o acolhimento dos usuários. Por outro, o grupo era também consideravelmente heterogêneo para que, não sendo abafadas, as controvérsias mobilizassem o diálogo e disparassem a construção de novos enunciados sobre a atividade de formação.

O exercício de instruções ao sósia disparou várias questões discutidas no terceiro encontro, como: a relação com os preceptores e outros funcionários dos serviços; as negociações de quais tarefas eles poderiam exercer nas unidades e como elas poderiam ser executadas; os impasses surgidos entre tarefas prescritas e os imprevistos do cotidiano do trabalho; os modos de lidar com a emoção e o impacto diante dos casos atendidos e a construção de uma postura profissional. Essas questões foram desenvolvidas por Conceição ${ }^{16}$ e Rosa ${ }^{17}$, mas aqui optamos por destacar apenas uma delas: a relação com o usuário do SUS. 
Essa relação foi identificada pelos estudantes como uma importante fonte de conflito em sua atividade, a partir do qual buscam construir um "profissionalismo" caracterizado como uma postura que mantém certo distanciamento, sem perder a sensibilidade que marca a prática do acolhimento no cuidado em saúde. Apresentamos esse tema a partir de recortes da transcrição do terceiro encontro numeradas por ordem das falas. Esse recorte se situa entre as falas 68 e 113 de um diálogo no qual constam 481 falas, no total.

O tema em questão é levantado a partir de uma fala da instrutora, proferida no segundo encontro, disparada pela interpelação da sósia: "O trabalho me acelera mais?”. Em seguida, a instrutora responde: "Você fica ansiosa, muito ansiosa, fica pensativa, com o que vão te falar, quais pessoas vai se deparar, com que tipo de comportamentos, e isso te deixa muito ansiosa”. É a partir dessa questão da ansiedade que outra estudante retoma o diálogo no terceiro encontro, como podemos notar a seguir:

68. Estudante 1: Eu estava pensando no que a $R$ [instrutora] falou, eu não sou do mesmo projeto, eu tenho um projeto diferente. Então eu não faço esse tipo de... não tenho esse acolhimento assim. Mas eu me identifiquei com as coisas que você sentia, assim, às vezes... você ficava ansiosa e eu também fico ansiosa e, às vezes, vai perguntando várias situações e você fala: "poxa, o quê que eu faria nessa situação?”, ou você se pega numa situação e fala: "Meu deus! Como eu vou fazer aqui??. Eu fico ansiosa quando a gente vai começar a fazer um livro, uma construção de um livro com um adolescente que a gente não sabe como aquele adolescente vai reagir e quando ele conta coisas que, assim, vão te... te... te impactar de alguma forma, mas você não pode transparecer isso para o adolescente. Então, isso me faz ficar ansiosa e, ainda, meio apreensiva: "Meu deus, eu tenho que me controlar, eu não posso... ou eu não posso chorar, ou eu não posso fazer uma cara de espanto, ou uma cara de 'Ai meu deus'”, sabe? Querer pegar no colo. Então, você tem que se manter ali, meio... como uma profissional com aquele menino, sem perder a... não é...

69. Instrutora: $A$ sensibilidade.

70. Estudante 1: É, sem perder sua sensibilidade. Você mostrar que você está ali disponível para ajudar, mas que você tem que ter essa barreira, essa barreira que eu digo assim, esse distanciamento, para que não se confundam as coisas.

71. Tutora: Não seria um distanciamento de ser fria...

72. Estudante 1: Isso! Não seria um distanciamento de ser fria, mas assim, dele não achar que a relação é de colega.

\section{$[\ldots]$}

80. Sósia: Mas eu achei muito legal isso que você falou de uma certa ansiedade que aparece ali, no trabalho. E eu queria perguntar se alguém mais se sente assim, como é que é, porque... muito interessante de você ter falado, é de uma certa posição profissional... você falou alguma coisa mais ou menos assim, nem amiga, nem profissional: fria. Como é que é isso, gente? Isso é bem interessante, né?

81. Estudante 2: Superdifícil! Quando se fala da questão grupo...

82. Estudante 1: é uma linha tênue, né, que você tem...

83. Estudante 2: Não tem jeito, elas vêm em cima de você, às vezes jogam umas coisas assim, em cima de você, que é, às vezes, até muito pesado. E às vezes você está tão com aquele controle que você faz para não chorar ou ter alguma reação, assim... negativa, mas, ao mesmo tempo, conseguir ajudar. Depois, no final, você fica, assim, eu me sinto... eu diria que fico meio cansada, dependendo do que... teve um dia que foi bem...

[...]

89. Sósia: Mas não pode chorar?

90. Instrutora: Eu não sei [falando com hesitação].

\section{1. [Risos]}

\section{2. [Várias pessoas falam juntas]}

93. Instrutora: Teve uma outra experiência que eu demonstrei, eu acho que eu tive um comportamento que, talvez, foi inadequado. Foi num varal de emoções, que foi uma atividade que a gente faz, que eles estendem uma toalha, uma canga e têm que jogar um retalho e, ali, externar alguma emoção. E aí, tinha uma senhora que falou que estava com o joelho... que ela tem artrite, e ela estava com o joelho muito... estava em crise. E aí ela falou que não ia participar. Só que, quando começou, ela foi a mais craque de todas, porque ela saiu pegando tudo. E aí eu fiquei apontando assim, "hahahahaha". Aí, depois a preceptora falou para mim, " $R$ [instrutora], você tem que fazer treinamento de cara de paisagem, porque você NÃO consegue”. Então, assim, eu acabei colocando aí. Mas não, gente... tá vendo? Eu fico assim: “o que pode e o que não pode?” Eu não sei.

94. Sósia: E que neutralidade é essa que a gente busca?

95. Instrutora: É, não dá. Não dá, porque, neutro, acho que é impossível.

96. Estudante 2: Ah, mas entra a questão do profissionalismo. Eu não sei se é questão do profissionalismo excessivo que a gente fica assim, "Ah, eu sou 
profissional, eu não...". Eu acho que fica um profissional biônico: "eu não posso chorar! Eu tenho que ficar aqui na posição".

97. Estudante 1: Sabe o que eu acho também? Até isso, de você querer ser um profissional, ainda mais agora, nós que estamos na academia. Então, a gente quer aprender como que a gente tem que ficar, se portar...

\section{Estudante 2: Ter postura...}

99. Estudante 1: Como a gente tem que ficar, se portar, mas tem aquilo da gente estar sentindo alguma coisa e a gente mesmo - pelo menos eu - ter medo de não conseguir controlar. Porque você falou, "não pode chorar?", pode chorar, mas, se eu não conseguir parar de chorar? Se eu ficar tão desestabilizada e não conseguir voltar ali e dar conta daquela situação que, naquele momento, eu sou a profissional que estou com aquele indivíduo, aquele paciente?

[...]

103. Instrutora: É, e você está na academia, olha para o profissional que está ali de frente, então você quer, de alguma forma, imitá-lo. Então, você olha, eu olho para a preceptora, e fico pensando, "Nossa, o jeito que ela age... pode, assim... não é a fórmula do bolo, mas é o mais aproximado que tenho do que seria certo, então eu vou tentar agir como ela".

\section{$[\ldots]$}

107. Sósia: Agora, eu acho que a minha pergunta... assim, não é que ela tenha uma resposta certa, ou que sim ou que não. Mas assim, esse controle tem a ver com ser um bom profissional? Eu não demonstrar ou eu não chorar, isso tem a ver com eu conseguir atuar da forma que eu devo?

108. Estudante 1: Acho que sim. Sim, está relacionado também. Porque, se você não consegue ter o mínimo de controle ali, como é que você vai atuar com aquela população? Eu acho assim, no começo, logo que eu entrei no projeto da Tutora $2 \ldots$ é um assunto que mexe muito comigo. Então, eu ia para lá, tinham os relatos, era certo, toda vez que eu saía, entrava no carro, mas eu chorava, chorava, chorava. Aí ficava dias pensando, aí chorando, chorando, chorando. [...] Não vou dizer que hoje eu não fico emocionada, fico, saio, choro. Mas assim, não é com aquela intensidade que eu... eu consigo controlar melhor.

109. Instrutora: $E$, eu acho que é um processo de adaptação.

110. Estudante 3: Eu também me sinto do mesmo jeito que ela. No começo eu também era assim, eu era muito emotiva. Então assim, tanto emotiva... e tanto assim... quando ela falou... tudo eu tinha que me envolver. Então, hoje, já na reta final, eu já me vejo mais madura. Tipo assim, eu me envolvo, mas assim, eu consigo colocar esse limite entre o que é profissional, entre o que é pessoal e entre o que eu posso ser como profissional. Então, eu passei por tudo isso. Só que, no meu caso, assim... é mais com relação às experiências, porque eu atuo com muito adolescente então ele sempre olha você como referência, então qualquer coisa que você venha falar, você pode ter uma repercussão. Eu atendi um caso de uma menina que a gente trabalhou muito com orientação sexual, muito com a questão do uso de preservativo, tudo. E ela... e aí, quando acabou a reunião, ela veio me procurar e falou assim para mim: "Ah, eu estou pensando em começar a relação sexual, e como foi a sua?", aí eu me vi. Falei assim, gente, como é que eu vou colocar a minha experiência... essa garota... eu posso interferir, influenciar, eu falei assim: "Eu acho que experiência é pessoal, eu tive a minha, você vai ter a sua. Só que eu acho que tudo tem que ter o consenso". Então, quando eu acabei aquilo, eu falei assim, gente eu nunca pensei que eu era tão madura $\operatorname{assim...}$

111. Instrutora: É, você conseguiu reagir...

112. Estudante 3: Eu consegui dar um limite ali, limitar ali. [...] ali eu consegui me ver madura profissionalmente. Não como uma estagiária, como uma profissional. Entendeu? Então assim, eu acho que a própria formação vai te dando isso, a própria experiência vai te dando isso.

Nessas falas percebemos a valorização da construção de uma "postura profissional", ou de um "profissionalismo", que consiste em atingir um equilíbrio entre o distanciamento frio e o descontrole emocional. Entre esses polos existem infinitas possibilidades de agir que dependerão do encontro singular que se dá na atividade do trabalhador (estudante bolsista PET-Saúde) dirigida ao usuário do serviço de saúde. Ainda, outras situações foram relatadas em torno da relação com o usuário, nas quais tanto o choro quanto o riso estiveram presentes, mostrando a invenção de vias possíveis.

Por outro lado, construir essa postura profissional no real da atividade não parece tarefa fácil. Como falávamos a respeito do novato, quando as prescrições não dão conta, a imitação dos pares mais experientes é uma maneira de lidar com esse conflito, e foi, da mesma forma, uma saída usada pelos estudantes quando relatam observar as ações dos preceptores. Entretanto, esse é um meio de agir que, assim como as prescrições, se mostra insuficiente. Se a qualidade do trabalho, nesse contexto, depende de um profissionalismo para o qual não há fórmulas a priori, como construí-lo? Como aprender a equilibrar e dosar 
distanciamento e descontrole? Como desenvolver uma sensibilidade? Os próprios estudantes, em suas falas, nos deram pistas: "a própria formação vai te dando isso, a própria experiência vai te dando isso".

Ao encararmos a formação como meio de desenvolvimento de recursos para agir, estamos, em primeiro lugar, afirmando a imprescindibilidade de viver os conflitos da atividade de trabalho para o qual se quer formar, oportunidade proporcionada pelo PET-Saúde. Em segundo lugar, assumimos como um indicador de que o processo de formação está em curso, a fabricação de saídas para que, diante dos impasses, o trabalho aconteça.

O impasse trazido pelos estudantes diz respeito a um "controle das emoções", à manutenção de uma postura, uma sensibilidade, na qual chorar e rir são ações possíveis se não significarem descontrole. Nos termos da clínica da atividade, isso representa a capacidade ou, ainda, a competência de servir-se das emoções para agir. O desenvolvimento dessa competência vai depender de uma migração funcional, a partir da compreensão de que a emoção é um evento de dupla tradução, um sistema que se expressa tanto por reações fisiológicas quanto por um vivido subjetivo que pode ser transformado em linguagem. Segundo Clot $^{18}$ :

Há uma diferença entre as duas traduções, mas é a interferência entre as duas que permite o desenvolvimento. Na tradução de um texto, para passar de uma língua à outra, é necessário pensar. No processo de dupla tradução, ou seja, de um só evento em duas traduções diferentes, há uma relação interfuncional entre a linguagem, o pensamento e as reações orgânicas (p.88).

Assim, o desenvolvimento consiste em flexibilizar esse sistema interfuncional, em expandir a possibilidade de se servir de suas emoções para pensar e, ao mesmo tempo, pensar para se servir das emoções. Para melhor compreender essa vitalidade das emoções, Clot nos oferece um interessante exemplo - o ofício de ator. Nele, para que a atividade ocorra, é preciso que as emoções se desloquem de meio para viver - a serviço das questões subjetivas vividas pelo sujeito no âmbito pessoal - e se tornem, num primeiro momento, objeto de trabalho - uma espécie de "matéria-prima" sobre a qual se debruça - para então servir como instrumento para a ação profissional. Tratam-se de migrações funcionais quando os atores retrabalham "as emoções que sentem habitualmente para tentar se servir delas com a finalidade de fazer viver o público"18 (p. 89). Os atores desenvolvem, com isso, a "tessitura da consciência", uma competência para mudar de registro, podendo, inclusive, tomar liberdades com as emoções - ao, por exemplo, chorar sem estar triste. Esse é um recurso que também pode ser utilizado por todos que praticam o cuidado em sua ação profissional:

\begin{abstract}
Somos tanto mais capazes de nos engajar em uma ação orientada aos outros, com os outros, quando temos essa forte tessitura da consciência. E isso se aprende coletivamente. O trabalho coletivo desenvolve a tessitura da consciência de cada um, a amplitude dos registros e a capacidade de mudar de registro. Nós somos todos um pouco atores da vida subjetiva (p. 90) ${ }^{18}$.
\end{abstract}

Sendo assim, para construir esse profissionalismo buscado pelos estudantes, é importante que eles sejam chamados à atividade de trabalho (por exemplo, via PET-Saúde) e à atividade de pensamento (por exemplo, via instruções ao sósia), que toma o trabalho como objeto, no coletivo. Trabalhando e retrabalhando coletivamente, repetindo sempre de forma única, a competência vai se construindo em um movimento inesgotável. O que se torna difícil caso o estudante esteja isolado do contexto para o qual pretende se formar ou de um coletivo com o qual possa dialogar. É justamente o conflito vivido pelo estudante a cada situação de trabalho - ou seja, essa linha tênue em que ele busca um equilíbrio entre a frieza e o possível descontrole resultante do envolvimento emocional - o motor que gera energia para o desenvolvimento da atividade de formação.

\section{Considerações finais}

A atividade de formação, objeto da pesquisa e intervenção que produziram as reflexões aqui apresentadas, foi tomada tanto com o objetivo de transformar o cenário que apontava para o adoecimento dos estudantes, quanto com o objetivo de produzir conhecimentos, ou seja, produzir pistas sobre como construir um processo de formação eficaz e salutar. Entendemos que esses dois objetivos estão interligados, de maneira que ambos são fonte e recurso de um desenvolvimento mútuo, a partir de um processo de migração funcional.

Mesmo entendendo que no PET-Saúde já havia uma análise do trabalho rotineira que se dava sem a intervenção do pesquisador - nos espaços de supervisão que ocorriam semanalmente -, ao experimentar o método de instruções ao sósia, a partir da troca com um novo interlocutor - a sósia/pesquisadora -, foi possível a esse grupo produzir outros enunciados, discutindo de forma não habitual os conflitos que aparecem no real da atividade. Vimos, com isso, que a instalação dessa metodologia de análise potencializou o desenvolvimento dos estudantes no seio da própria atividade de formação: vivida a princípio como meio de aprender, torna-se, com a intervenção, 
objeto de análise. A partir daí, é possível debruçar-se sobre ela, observá-la, para, enfim, construir novos instrumentos para a ação profissional.

Essa abordagem teórico-metodológica se distingue daquelas intervenções que, embora também busquem a transformação das situações de trabalho, resultam em recomendações ou operam pelo estabelecimento de nexos causais a partir do levantamento sistemático de fatores de risco. Por outra via, entendemos, a partir de Canguilhem, que a saúde é uma margem de segurança, uma espécie de arsenal de ações possíveis, inevitavelmente convocada pelo real da atividade. Nesse sentido, investimos no fortalecimento e na ampliação dos recursos para a ação dos estudantes e, consequentemente, no desenvolvimento dessa margem de segurança, a partir da discussão coletiva do trabalho, entendido como atividade. Em última instância, apostamos que ao operar na saúde estamos interferindo no contexto adoecedor.

Assim, quando a atividade de formação inclui a criação de contextos dialógicos, que tomam a situação de trabalho dos formandos como objeto de análise coletiva, ela tem condições de se configurar também como atividade de cuidado desses sujeitos. Isso ocorre na medida em que se sustente um diálogo com e entre os modos de estar e se constituir na vida e no trabalho, de modo situado, conectado com os desafios do real, com suas nuances e singularidades. Tal projeto formativo contribui para identificar, criar e fortalecer movimentos, ações e coletivos que estejam enfraquecidos. Um ofício que não tem oportunidade de ser tomado como objeto de análise coletiva entre pares, deixa de ser um recurso para o desenvolvimento dos sujeitos, é um ofício maltratado, tornando-se fonte de sofrimento, tal como evidenciado por Clot $^{4,5}$.

Inspiradas por Tosquelles, podemos dizer que é cuidando do trabalho também nos contextos da formação profissional, que é possível formar e cuidar continuamente dos trabalhadores e dos aprendizes que circulam nestes contextos. Eis aí nossa aposta em investir, junto com a clínica da atividade, naquilo que o trabalho comporta como operador de saúde.

\section{Contribuições de autoria}

Conceição CL e Rosa RPF coelaboraram a intervenção descrita no artigo, desenvolvendo a escrita, revisão e aprovação da versão final do trabalho. Santorum K participou ativamente da discussão dos resultados, desenvolvendo a escrita, revisão e aprovação da versão final do trabalho.

\section{Referências}

1. Osorio-da-Silva C, Ramminger T. O trabalho como operador de saúde. Cien Saude Colet. 2014;19(12):4751-8.

2. Canguilhem, G. O normal e o patológico. $3^{\mathrm{a}}$ ed. Rio de Janeiro: Forense Universitária; 1990.

3. Brasil. Ministério da Saúde. Portaria Interministerial $n^{\circ} 421$, de 3 de março de 2010. Institui o Programa de Educação pelo Trabalho para a Saúde (PET Saúde) e dá outras providências. Diário Oficial da União. 5 mar 2010. Seção 1:52-53.

4. Clot Y. Trabalho e poder de agir. Belo Horizonte: Fabrefactum; 2010.

5. Clot Y. A função psicológica do trabalho. Petrópolis: Vozes; 2007.

6. Batista M, Rabelo L. Imagine que eu sou seu sósia... Aspectos técnicos de um método em clínica da atividade. Cad Psicol Soc Trab. 2013;16(1):1-8.

7. Osorio-da-Silva C. Pesquisa e intervenção: movimentos que se cruzam e coexistem, em mútua interferência. In: Banks-Leite L, Smolka ALB, Anjos DD, organizadores. Diálogos na perspectiva histórico-cultural: interlocuções com a clínica da atividade. Campinas: Mercado das Letras; 2016. p. 153-168.

8. Soares JDL, Nogueira SE. A implantação dos programas Pró e PET-Saúde no território do entorno do IFRJ campus Realengo: uma experiência de integração ensino-serviçocomunidade. In: Soares JDL, Nogueira SE, organizadores. Tecnologias do cuidado no SUS: algumas experiências do PET-Saúde Redes de Atenção na zona oeste do Rio de Janeiro. Rio de Janeiro: PoD; 2016. p. 11-28.

9. Clot Y. L'échange avec un «sosie» pour penser l'expérience: un essai. Société Française. 1995;3(53):51-5.

10. Franco TB, Merhy EE. O reconhecimento de uma produção subjetiva do cuidado. In: Franco TB, Merhy EE. Trabalho, produção do cuidado e subjetividade em saúde: textos reunidos. São Paulo: Hucitec; 2013. p. 151-71.

11. Clot Y. A psicologia do trabalho na França e a perspectiva da clínica da atividade. Fractal Rev Psicol. 2010b;22(1):207-34.

12. Clot Y. A contribuição de Tosquelles à clínica do trabalho. Trab Educ. 2013;22(1):199-208. 
13. Jackson Filho JM. Engajamento no trabalho, impedimentos organizacionais e adoecer: a contribuição da Ergonomia da Atividade no setor público brasileiro. Rev Bras Saúde Ocup. 2015;40(131):98-108.

14. Vasconcelos R, Lacomblez M. Redescubramo-nos na sua experiência: o desafio que nos lança Ivar Oddone. Laboreal, 2005;1(1):38-51.

15. Clot Y. La formation par l'analyse du travail: pour une troisième voie. In: Maggi B. Manières de penser, manières d'agir em éducation et em formation. Paris: Presses Universitaires de France; 2000. p. 133-56.

16. Conceição CL. A formação pela ação: experimentando o ofício de analista do trabalho pela perspectiva da Clínica da Atividade [dissertação]. Niterói: Universidade Federal Fluminense; 2016.

17. Rosa RPF. Terapia ocupacional e clínica da atividade: intercessões nos debates da atividade de formação [tese]. Niterói: Universidade Federal Fluminense; 2017.

18. Clot Y. A interfuncionalidade dos afetos, das emoções e dos sentimentos: o poder de ser afetado e o poder de agir. In: Banks-Leite L, Smolka ALB, Anjos DD, organizadores. Diálogos na perspectiva histórico-cultural: interlocuções com a clínica da atividade. Campinas: Mercado de Letras; 2016. p. 153-68. 